\title{
NEW PRECAST BRIDGE GIRDER WITH COMBINED PRESTRESSING
}

Traditionally, the major part of highway bridges in Slovakia is realized using the precast concrete technology. The common Slovak precast girders are produced to the $34 \mathrm{~m}$ length as one element. Nowadays, there is an increasing demand for more economical and resisting bridge structures with longer spans. The company Vahostav-Sk-PREFA, Ltd as the main supplier of precast elements for highwaybridge 207, in cooperation with theUniversity of Zilina and the designer company Dopravoprojekt Inc. Liptovsky Mikulas, developed a new precast girder MDP for the span $38 \mathrm{~m}$ with combined prestressing. Some experiences and results of verifying flexural test with numerical analysis of that girder are presented in this paper.

\section{The Basic Parameters of the Bridge Girder}

The majority of Slovak highway bridges are made of standardized "I" and "T" - shaped precast prestressed girders with cast-in place concrete deck slab. The innovative features allow for spans up to $38 \mathrm{~m}$ and increasing girder spacing up to $1680 \mathrm{~mm}$. The girders have a construction depth $1900 \mathrm{~mm}$, with constant top and bottom flange $800 \mathrm{~mm}$ wide. The girder's cross section is shown in Fig. 1. The MDP 38 girder has a combined prestressing. The girders are pre-tensioned with 28 strands $\phi 15.5 \mathrm{~mm} / 1800 \mathrm{MPa}$ with low relaxation (and 2 strands in top flange). The spacing between prestressing strands is $50 \mathrm{~mm}$. The post-tensioning is realised by three tendons consistings of 4 strands $\phi 15.5 \mathrm{~mm}\left(A_{p}=141.5 \mathrm{~mm}^{2}\right)$. Reinforcement was realised using ordinary steel BS 500 . The designed concrete strength class of girders is $\mathrm{C} 45 / 55$.

The precast bridge superstructure is built by girder placing on the abutments and next the cross beam and the cast-in-place reinforced concrete deck with a depth of $200 \mathrm{~mm}$ is cast.The composite deck is designed from concrete strength class $\mathrm{C} 30 / 37$. The prestressed girder MDP 38 was designed according toSlovak design code STN 731251 [1], CSN 736207 [5] and STN 736203 [4]. The FEM computer system "Nexis2" was applied to determine the load effect to the shell-beam continual FE model. The material properties for the concrete cross-section model as well as the criteria for the steel bar distance at the concrete cover were applied according to the Europan standard STN EN 1992-1-1 for the design precedure.

\section{Mechanical and Rheological Properties of Concrete}

The properties of concrete were evaluated in the preparation stage with special care, since they have a decisive influence on the structural properties of the girder. Another important feature is the time development of the concrete compressive strength that determines the time in which the prestressing force transfer into the girder can be started. The prestress force in practice is implemented in the time period from 15 to 48 hours after girder casting. The criteria for the release of prestressing require the minimal compressive strength, the modulus of elasticity and rheological properties of the young concrete. Therefore, the concrete properties in time were analyzed. The measurements of concrete strength and the modulus of elasticity were performed at concrete age of 26 $36-48$ - 186 hours ( 7.7 days), and 690 hours (28.7 days). The specimens were tested in a curing room with temperature of 20 $\pm 2{ }^{\circ} \mathrm{C}$ and relative humidity of $80 \%$. Thecube compressive strengths were measured on $150 \times 150 \times 150 \mathrm{~mm}$ specimens. Three specimens were tested at different time and the average value was taken to the next analysis. The modulus of elasticity of concrete was measured on a specimen of $100 \times 100 \times 400 \mathrm{~mm}$. The modulus of elasticity was measured by static and dynamic testing. The total 20 concrete prisms were tested. Three prisms were used for measurement of shrinkage. Fig. 2 shows time development of the concrete strength and the modulus of elasticity.

Starting cambers of the girder were calculated from real parameters of concrete at the important construction stage. Table 2

Starting cambers of the girder in building phases

Tab. 1

\begin{tabular}{|c|c|c|c|c|c|}
\hline $\begin{array}{c}\text { Phase } \\
\text { No. }\end{array}$ & Phase definition & $\begin{array}{c}\text { Time } \\
(\text { hour })\end{array}$ & $\begin{array}{c}\text { ftest } \\
(\mathrm{mm})\end{array}$ & $\begin{array}{c}\text { fmodel } \\
(\mathrm{mm})\end{array}$ & $\begin{array}{c}\text { fcalc } \\
(\mathrm{mm})\end{array}$ \\
\hline 1. & $\begin{array}{c}\text { Prestressing transfer to the } \\
\text { concrete }\end{array}$ & 48 & 28.50 & 26.30 & 32.15 \\
\hline 2. & $\begin{array}{c}\text { Post-tensioning of added } \\
\text { strands }\end{array}$ & 168 & 50.80 & 50.16 & 57.02 \\
\hline
\end{tabular}

\footnotetext{
* Martin Moravcik, Petra Bujnakova

Facultyof Civil Engineering, UniversityofZilina, , Slovakia, E-mail: martin.moravcik@fstav.uniza.sk
} 


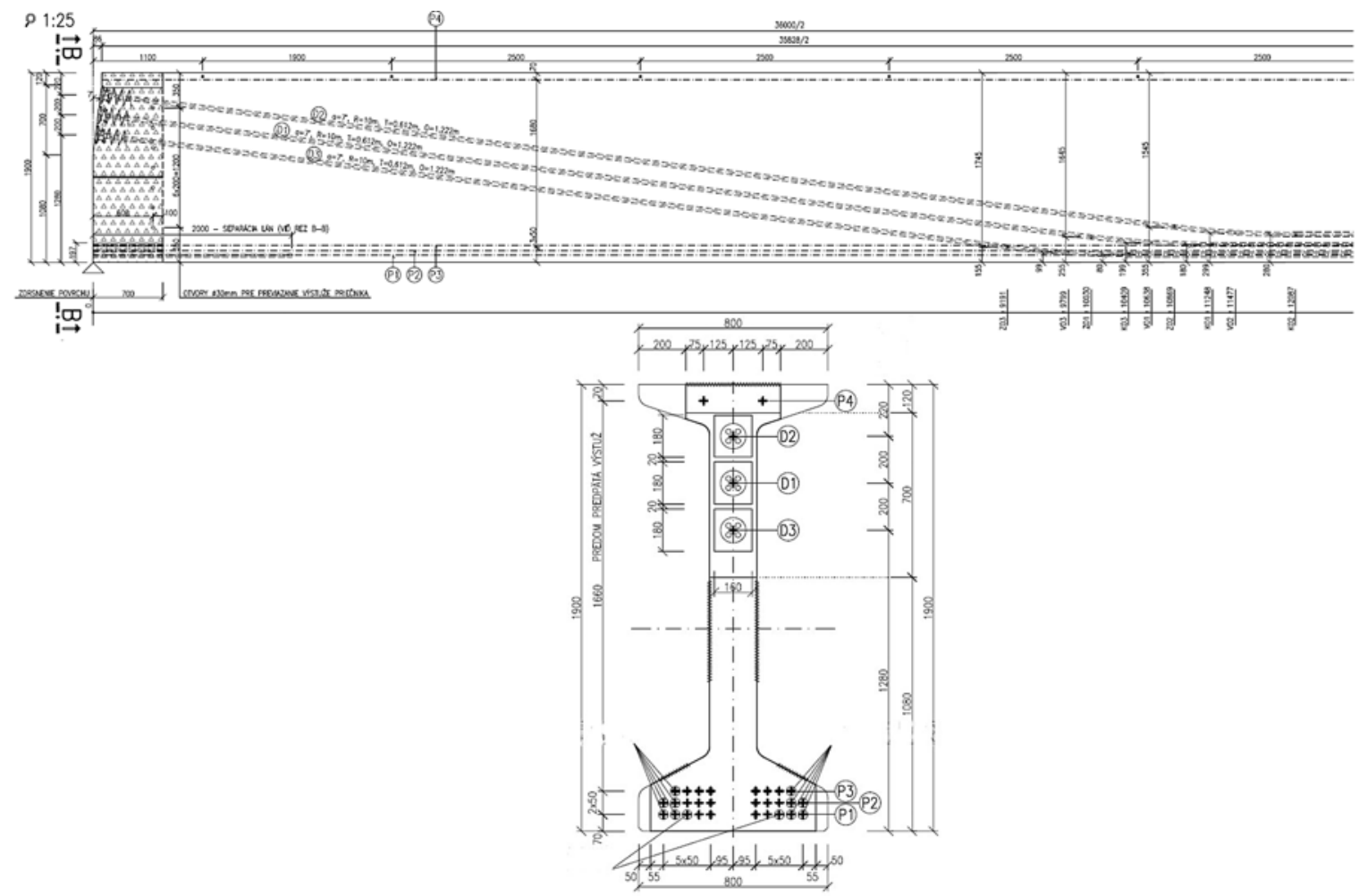

Fig. 1 The longitudinal section and front view of the girder MDP 38

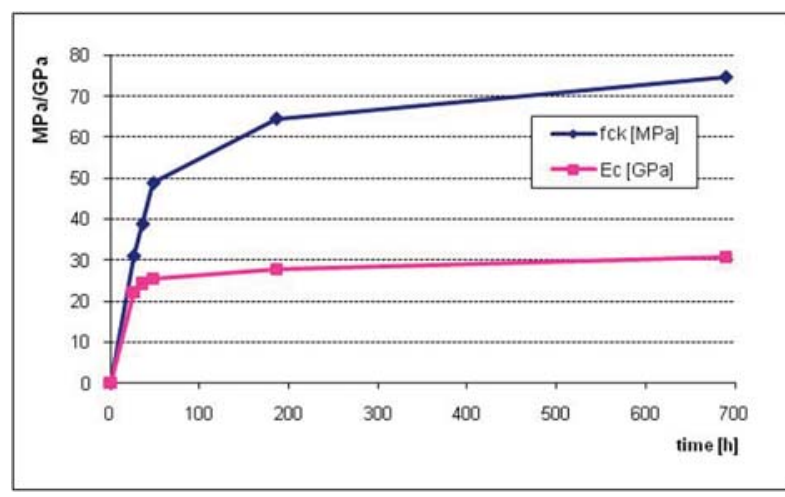

Fig. 2 The development ofmodulus of elasticity and the compressive strength

compares the experimental and calculated values of the camber at the pre and post- tensioning phases.

\section{Static Load Test}

The MDP 38 prestressed girder was tested using three-point flexure set-up to determine a flexural cracking moment and a ultimate moment capacity. The test setup is illustrated in Fig. 3. The tested girder was supported by rubber bearings placed on concrete panels $\left(l_{\text {eff }}=37.3 \mathrm{~m}\right)$. The load force was manually applied using the prestressing compacting machine. The $60 \times 60 \times 30 \mathrm{~mm}$ rubber pad was placed between the hydraulic jack "PAUL" and the girder to create a distributed contact area. Concrete blocks over the tested girder were used as a counterweight during the loading process. Such non-traditional set-up was chosen to achieve a high ultimate capacity of the hydraulic jack $(4000 \mathrm{kN})$. The load was applied incrementally step by step and monitored using a dynamometer type PROSEQUE.

The prestressing force was recorded by four elastomagnetic sensors, using PROJSTAR system PSS20. One sensor was located on the top of the prestressing strand and three sensors were fixed on bottom strands. The prestressing was controlled permanently - after release of prestressing (2 days), after post-tensioning ( 7 days), and before the static load test (14 days).

The concrete strain was controlled at the mid span using strain gauges. Three strain gauges were installed on both sides of the girder at the bottom, in the middle and at the top. Deformation was measured using a vertical displacement transducer at the quarter of span, at the mid of span, and close at the support. Possible settlements of abutments were checked geodetically.

Basic mechanical properties of the concrete and prestressing strands were verified before the static load test. The concrete specimens reached the following vallues of the important parameters:

- The mean compressive strength $f_{c m}=44.71 \mathrm{MPa}$.

- The mean tensile strength $f_{c t m}=2.23 \mathrm{MPa}$.

- The mean modulus of elasticity $E_{c}=28989 \mathrm{MPa}$. 
The measured parameters of prestressing strands:

- The minimum value of ultimate strength $f_{p}=1851 \mathrm{MPa}$

- The minimum value of yield strength $f_{p 0,2}=1686 \mathrm{MPa}$.

- The modulus of elasticity $E_{p}=189 \mathrm{GPa}$.

Load steps of the structure were realised incrementally with unloading steps at the level of the first visible bending crack and the predicted Ultimate Limit State (ULS), see Table 2. After each load increment, loading was stopped to record the deformation, the concrete strain and to check any visible cracking. At the point of the first visible crack, the loading was noted and all cracks were mapped.

Characteristic deflection during the load test

Tab. 2

\begin{tabular}{|c|l|c|c|c|}
\hline $\begin{array}{c}\text { Phase } \\
\text { No. }\end{array}$ & \multicolumn{1}{|c|}{ Phase definition } & $\begin{array}{c}\text { Load } \\
P(\mathrm{kN})\end{array}$ & $\begin{array}{c}\text { Experiment } \\
f_{\text {exp }}(\mathrm{mm})\end{array}$ & $\begin{array}{c}\text { Analysis } \\
f_{\text {model }}(\mathrm{mm})\end{array}$ \\
\hline 1. & $\begin{array}{l}\text { Self-weight of the bridge } \\
\text { deck }\end{array}$ & 177.40 & -15.86 & -15.97 \\
\hline 2. & $\begin{array}{l}\text { Other self-weight and } \\
\text { permanent load }\end{array}$ & 400.60 & -44.42 & -44.94 \\
\hline 3. & $\begin{array}{l}\text { Predicted cracking } \\
\text { moment }\end{array}$ & 595.70 & -75.47 & -70.0 \\
\hline 4. & The first visible crack & 750.00 & -88.35 & -89.87 \\
\hline 5. & $\begin{array}{l}\text { Ultimate girder bending } \\
\text { capacity }\end{array}$ & 1183.2 & -129.33 & -156.06 \\
\hline
\end{tabular}

a) moving load scheme ZZI according to Slovak standard STN 736203

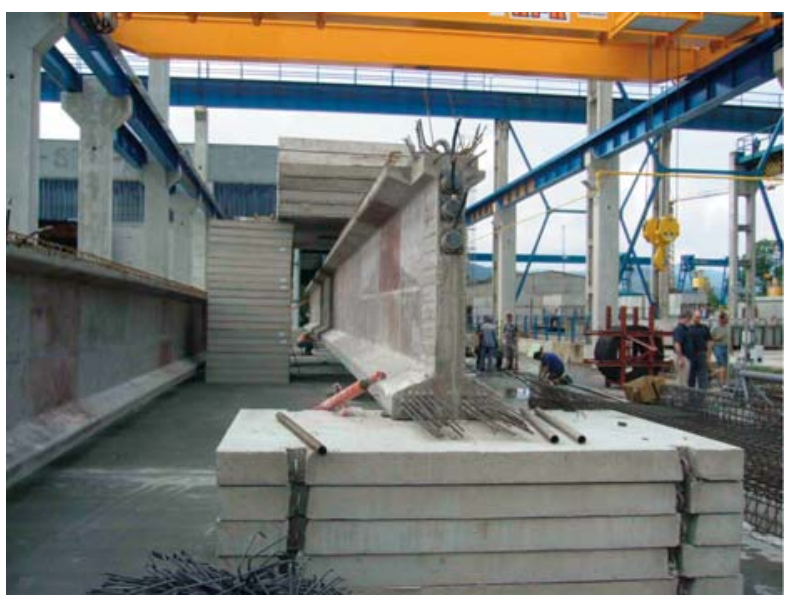

Fig. 3 The test seting up

\section{Numerical Analysis}

The FE numerical analysis was performed to simulate the previously described bending test. The numerical model of the tested girder was created in computing system ATENA 2D that allows to perform a nonlinear finite element analysis of the prestressed structures under static loads. The system enables to consider material and geometrical nonlinearities of the concrete structure and nonlinear solution principles. The constitutive relations are formulated for the plane stress state. A smeared approach was used to model the material properties for fixed cracks and the longitudinal and transversal reinforcement. Prestressing strands are modelled as discrete elements and for all reinforcement the bilinear stressstrain relationship was used. The prestressing force applied to the model was reduced considering the calculated prestress losses. Concrete is represented by the material model SBETA with characteristic values of the compressive strength and the modulus of elasticity from the experimental testing. Perfect bond between the concrete and reinforcement is assumed applying the smeared concept.

Loading is applied by prescribing the vertical displacement at the middle of the loading plate with constant increments of $0.1 \mathrm{~mm}$. The overall response is recorded at two monitoring points - loading as the reaction at the top point and the deflection at the bottom of the girder.

\section{Some Results of the Static Test}

Results of the FEM analysis were compared with results obtained by experimental testing. The maximum value of the camber along the longitudinal axis gained immediately after the pre- tensioning phase (around 48 hours) was observed as well as the value of camber after the post-tensioning phase (around 168 hours), see Tab. 1. There can be seen a good coincidence between experimental and theoretical values of starting camber. The defined material model of the girder well corresponded with real concrete parameters.

The characteristic load vs. the midspan deformation of the girder is shown in Tab. 2. As can be seen the predicted relationship of strain courses in fibres of concrete cross-section and tension force increments in the strands shows a good agreement with the measured structural response, see Figs. 4, 5. The typical stiffness reduction in load steps after cracking was not significant and the short-term load response of that girder was almost linear.

Cracking of the girder during flexural test was propagated as follows. The first visible crack was noted near the midspan at the load level of $750 \mathrm{kN}$. Additional cracks developed along the span as the load was increased. The real crack propagation in the ULS is shown in Fig. 6. The critical crack width $0.2 \mathrm{~mm}$ was observed on the load level around $1000 \mathrm{kN}$ that means aproximately $82 \%$ of the exploitation of cross-section capacity. The recorded spacing of cracks well coincided with calculated values in load steps.

\section{Application}

Nowadays, the precast prestressed bridge composed of MDP 38 girders, made in continuos structural system is the longest bridge 


\section{coMMNICaIIONS}

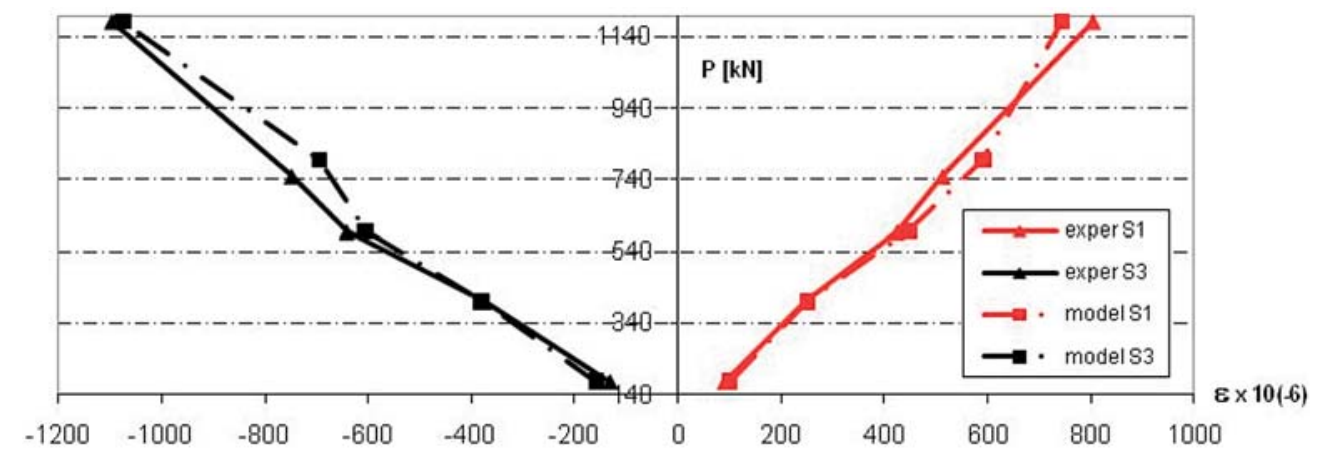

Fig.4 Strain in compressed and tensioned fibres of concrete cross-section in $l_{\text {eff }} / 2$

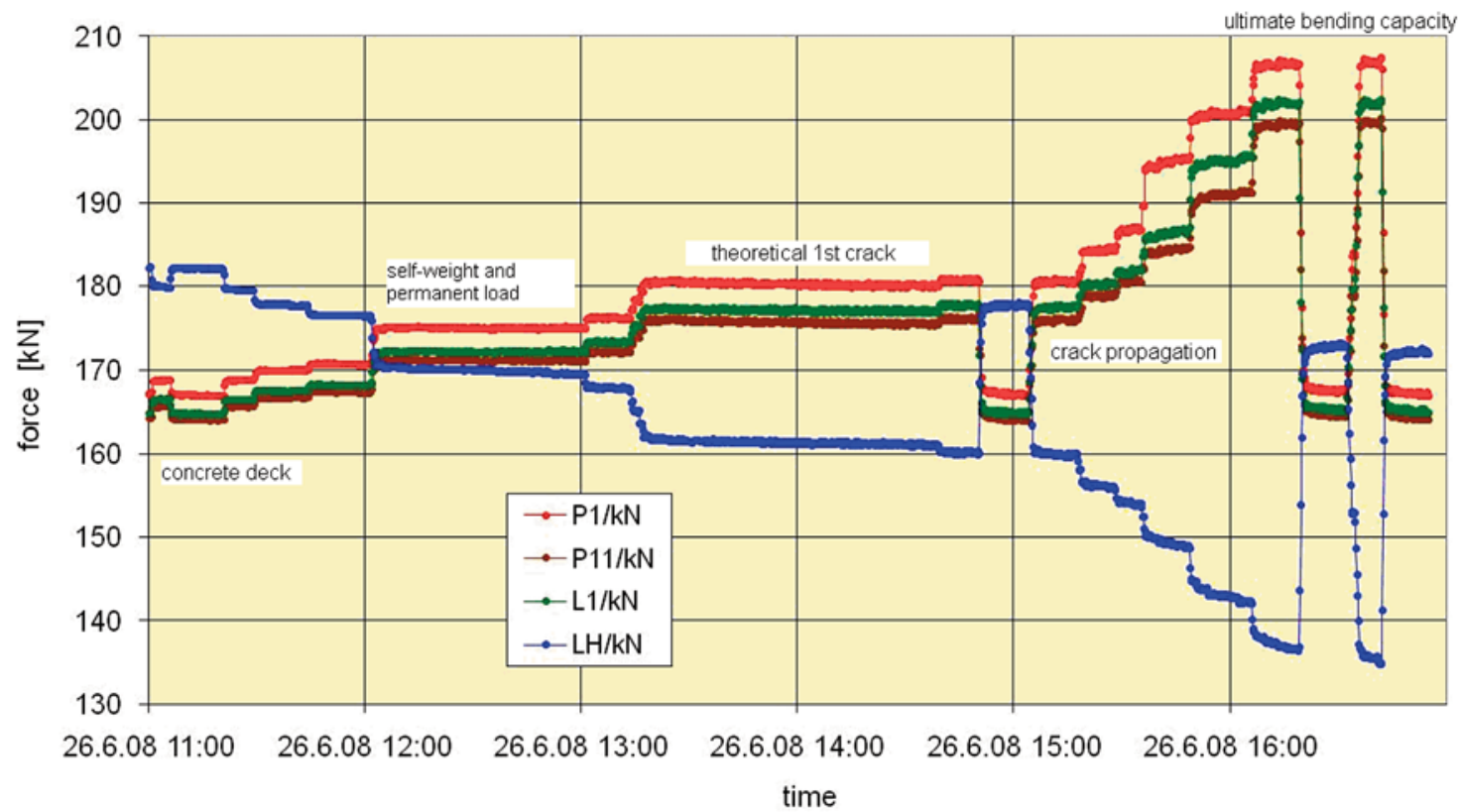

Fig. 5 Development of forces in observed strands in $l_{\text {eff }} / 2$

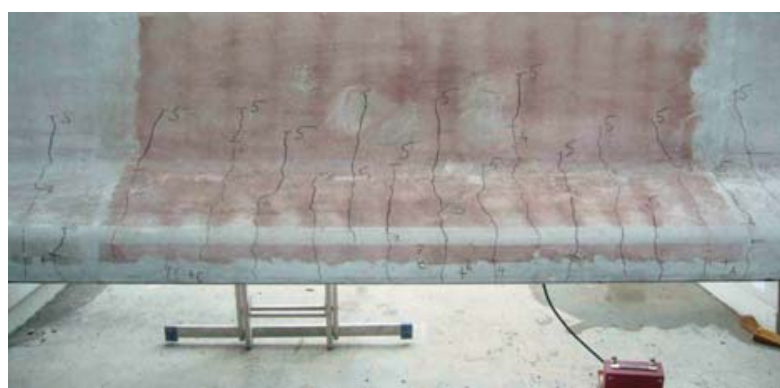

Fig. 6 Crack propagation at the bottom flage in the middle cross-section

in Slovakia. Transportation and erection of these bridge girders during construction of highway bridge 207, "Sverepec - Vrtizer" is illustrated in Fig. 7.

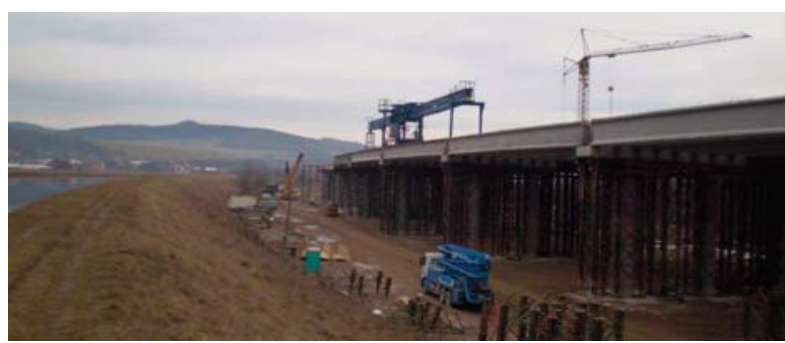

Fig. 7 Construction of the highway bridge 207

\section{Conclusion}

The experimental analysis showed that the structural behaviour of the girder corresponded to the requirements of design assumptions. The sufficient load carrying capacity was approved 
and the manufactured girder can serve reliably and can be used in practice. Neither a structural destruction nor the load on predicted resistance level was reached. The performed FEM model well simulated the behaviour of real precast girder. Experimental and theoretical values of the starting camber, deformations (in $l_{\text {eff }} / 2$, and $l_{\text {eff }} / 4$ ), concrete strains and forces in strands showed a good coincidence. This kind of model can be used for development of other commercial types of precast bridge girders in the future.

\section{Acknowledgement}

This research work has been supported by the VEGA agency, $1 / 0461 / 10$ and as the result of the project implementation: "Support of Research and Development for Centre of Excellence in Transport Engineering" (ITMS: 26220120031) supported by the Research\& Development Operational Programme funded by the ERDF.

\section{References:}

[1] STN 73 1251, Design of Structures of Prestressed Concrete.

[2] STN EN 1992-1-1, Design of Concrete Structures, Part 1, General Rules

[3] STN EN 1992-1-2, Design of Concrete structures, Part 2. Concrete Bridges

[4] STN 73 6203, Loading on Bridges.

[5] CSN 73 6207, Design of Prestressed Bridges.

[6] MORAVCIK, M., CHANDOGA, M., JAROSEVIC, A. et al.: Load Test of Prestressed Girder MDP 38 m, Report, Zilina, Slovakia, 2008. 